\title{
Structural and thermal properties of vanadium tellurite glasses
}

Rajinder Kaur, Ramandeep Kaur, Atul Khanna, and Fernando González

Citation: AIP Conference Proceedings 1942, 070028 (2018); doi: 10.1063/1.5028826

View online: https://doi.org/10.1063/1.5028826

View Table of Contents: http://aip.scitation.org/toc/apc/1942/1

Published by the American Institute of Physics 


\title{
Structural and Thermal Properties of Vanadium Tellurite Glasses
}

\author{
Rajinder Kaur ${ }^{1}$, Ramandeep Kaur ${ }^{1}$, Atul Khanna ${ }^{1, a)}$, Fernando González ${ }^{2}$ \\ ISensors and Glass Physics Laboratory, Department of Physics \\ Guru Nanak Dev University, Amritsar, Punjab,India \\ 2Department of Chemistry and Process \& Recourse Engineering, University of Cantabria, Spain
}

a) Corresponding author: AtulKhanna: atul.phy@gndu.ac.in

\begin{abstract}
V}_{2} \mathrm{O}_{5}-\mathrm{TeO}_{2}$ glasses containing 10 to $50 \mathrm{~mol} \% \mathrm{~V}_{2} \mathrm{O}_{5}$ were prepared by melt quenching and characterized by Xray diffraction (XRD), density, Differential Scanning Calorimetry (DSC) and Raman studies.XRD confirmed the amorphous nature of vanadium tellurite samples. The density of the glasses decreases andthe molar volume increases on increasing the concentration of $\mathrm{V}_{2} \mathrm{O}_{5}$. The thermal properties, such as glass transition temperature $\mathrm{T}_{\mathrm{g}}$, crystallization temperature $T_{c}$, and the melting temperature $T_{m}$ were measured. $T_{g}$ decreases from a value of $288^{\circ} \mathrm{C}$ to $232^{\circ} \mathrm{C}$. The changes in $\mathrm{T}_{\mathrm{g}}$ were correlated with the number of bonds per unit volume, and the average stretching force constant. Raman spectra were used to elucidate the short-range structure of vanadium tellurite glasses.
\end{abstract}

\section{INTRODUCTION}

Tellurium dioxide $\left(\mathrm{TeO}_{2}\right)$ is the most stable oxide of tellurium (Te). The transitional position of Te between metals and non-metals, has long held special significance and the properties of tellurium oxide such as good glass stability and durability, low melting point, non-hygroscopic nature; high refractive indices, wide optical transmission window, and exceptional non-linearoptical properties are the driving force behind the enormous interest in the synthesis and characterization of tellurite materials[1]. Due to aforementioned unique properties, the tellurite glasses have wide range of applications in gas sensors, memory switching devices, up-conversion laser and optical waveguides.In tellurite glasses, there are two types of structural units; $\mathrm{TeO}_{4}$ trigonalbipyramids (tbp) and $\mathrm{TeO}_{3}$ trigonal pyramids (tp). $\mathrm{TeO}_{2}$ has two crystalline phases, namely $\alpha-\mathrm{TeO}_{2}$ (paratellurite) and $\beta-\mathrm{TeO}_{2}$ (tellurite) with tetragonal and orthorhombic structures respectively. The structure of $\alpha-\mathrm{TeO}_{2}$ consists of a three-dimensional (3D) network built up from $\mathrm{TeO}_{4}$ subunits, with each oxygen atom shared by two units, bonded in the equatorial position to one tellurium atom and in the axial positionto another tellurium atom. On slowly heating the pure glass, $\gamma-\mathrm{TeO}_{2}$ phase is formed which gets modified to $\alpha-\mathrm{TeO}_{2}$ with further thermal energy while the $\beta-\mathrm{TeO}_{2}$ phase is not observed during this process[2]. Earlier, pure tellurite glasses were formed at very high quenching rates of $\sim 10^{5} \mathrm{Ks}^{-1}$ by twin roller quench technique but recently it has been synthesized in bulk using intermittent quenching technique[3]. The molecular dynamics simulation studies show the coordination number of Te-O to be 3.69, while by neutron diffraction studies, it is reported to be 3.73 . The $\mathrm{N}_{\mathrm{Te}-\mathrm{O}}$ values calculated from neutron diffraction studies show good agreement with the results from Raman spectroscopy[2].

Tellurium dioxide is a conditional glass former and it forms glasses easily when mixed with metal oxides such as $\mathrm{Li}_{2} \mathrm{O}, \mathrm{BeO}, \mathrm{MgO}, \mathrm{SrO}, \mathrm{V}_{2} \mathrm{O}_{5}$ etc. The addition of modifiers in tellurite glass causes the breakage of Te-O-Te linkages and to break one edge in $\mathrm{TeO}_{2}$, an oxygen atom must be supplied to complete the octets of the two cations involved. Therefore different oxides of groups III, IV, or V of the periodic table can be used to synthesize binary tellurite glasses. It is reported that with increase in proportion of modifiers, the network first breaks down to crosslinked and branched chains and finally to un-branched chains[4]. Generally, this deformation is related with the change in the coordination structure of the tellurium atoms. For instance, $\mathrm{TeO}_{4}$ (trigonal bipyramids) converts into $\mathrm{TeO}_{3}$ (trigonal pyramids) with the addition of the alkali oxides[5].

Pure, single crystal, vanadium penta-oxide $\left(\mathrm{V}_{2} \mathrm{O}_{5}\right)$ is an insulator due to the presence of empty d-bands. After growing it from the melt, it is found to be an n-type semiconductor having activation energy of around $0.28 \mathrm{eV}$. This 
might happen because of the impurities arising from doping or due to the loss of oxygen from the melt[ $[4] \cdot \mathrm{V}_{2} \mathrm{O}_{5}$ can act as a network former, and also as network modifier in the presence of $\mathrm{TeO}_{2}$ since it produces structural modification in the tellurite network. On mixing it with $\mathrm{TeO}_{2}$, it forms glasses in the composition range of 7.5 to 58 mol\% of $\mathrm{V}_{2} \mathrm{O}_{5}$ [1]. The glass transition temperature $\left(\mathrm{T}_{\mathrm{g}}\right)$ depends on the concentration of $\mathrm{V}_{2} \mathrm{O}_{5}$ and it is observed that the glass structure gradually changes from the continuous telluritenetwork to the continuous vanadate network with increasing $\mathrm{V}_{2} \mathrm{O}_{5}$ content from 20 to $50 \mathrm{~mol} \%$, with large concentration of triangularly co-ordinated Te atoms. However, the glasses containing less than $20 \mathrm{~mol} \% \mathrm{~V}_{2} \mathrm{O}_{5}$ have a continuous tellurite network that contains mostly four-coordinated Te atoms [6]. The aim of this work is to study the compositional dependence of $\mathrm{T}_{\mathrm{g}}$ and short-range structural properties of vanadium tellurite glasses by DSC and Raman spectroscopy.

\section{EXPERIMENTAL}

\section{Glass Preparation}

Vanadium tellurite glasses of compositions: $x \mathrm{~V}_{2} \mathrm{O}_{5}-(100-x) \mathrm{TeO}_{2}$ where $x=10,30,40,50 \mathrm{~mol} \%$ were prepared using $\mathrm{TeO}_{2}$ (Sigma Aldrich India 99\%) and $\mathrm{V}_{2} \mathrm{O}_{5}$ (Sigma Aldrich India $99.6 \%$ ) by normal quenching. The appropriate amount of these starting materials were weighed and mixed together in an agate mortar-pestle. The mixture was put into a platinum crucible $\left(25 \mathrm{~cm}^{3}\right)$. The batch mixture was first sintered at $250^{\circ} \mathrm{C}$ in electric furnace for $3 \mathrm{~h}$ followed by second sintering at $450^{\circ} \mathrm{C}$ for $2 \mathrm{~h}$. The temperature of furnace was slowly raised to $700^{\circ} \mathrm{C}$ and the glass melt was kept at this temperature for $1 \mathrm{~h}$ before quenching it on a heavy brass plate. The samples were immediately annealed at $230^{\circ} \mathrm{C}$ for 1 hto reduce thermal stresses in the samples. The samples were characterized by density measurements, XRD, DSC and Raman studies.

\section{X-ray diffraction (XRD)}

XRD studies were carried out on Shimadzu XRD-7000 X-ray diffractometer with $\mathrm{Cu} \mathrm{K}_{\alpha 1}$ radiation $(\lambda=1.54056$ $\AA$ ) in the $2 \theta$ range of $15^{\circ}-70^{\circ}$. The X-ray tube was operated at $40 \mathrm{kV}$ and $30 \mathrm{~mA}$ and the scattered X-ray intensity was measured with a scintillation detector.

\section{Density measurement}

Density of glasses was determined by Archimedes method using dibutylphatalate as the immersion fluid. The error in density was in the range of \pm 0.01 to $0.04 \mathrm{~g} \mathrm{~cm}^{-3}$.

\section{Differential Scanning Calorimetry (DSC)}

DSC studies were performed on powdered samples(20-50 mg)in platinum pans on SETARAM SETYS 16 TGDSC system at heating rate of $10^{\circ} \mathrm{C} \mathrm{min}^{-1}$ under air-flow conditions in the temperature range of $200-800^{\circ} \mathrm{C}$. The maximum uncertaintyin the measurement of glass transition (mid-point), crystallization (peak-point) and melting temperatures (peak-point) is $\pm 1^{\circ} \mathrm{C}$.

\section{Raman spectroscopy}

Raman studies were performed on powdered samples using RenishawIn-Via Reflex micro-Raman spectrometer with $488 \mathrm{~nm}$ argon ion laser $(50 \mathrm{~mW})$ as excitation source, diffraction grating having 2400 lines $\mathrm{mm}^{-1}$, an edge filter and a Peltier cooled CCD detector. Measurements were carried out at room temperature in an un-polarized mode and in the wave number range of 30 to $1000 \mathrm{~cm}^{-1}$ at a spectral resolution of $1 \mathrm{~cm}^{-1}$.

\section{RESULTS AND DISCUSSION}

XRD patternsof samples are shown in Figure 1. The absence of sharp peaks and a broad hump at $\sim 27^{\circ}$ confirms the amorphous nature of the vanadium tellurite glasses.

From density measurements (Figure 2), it is observed that, as the vanadium oxide content increases the density of samples decreases from $5.22 \mathrm{~g} \mathrm{~cm}^{-3}$ to $3.96 \mathrm{~g} \mathrm{~cm}^{-3}$. The linear decrease in density can be explained by the fact that the Te atoms are replaced by $\mathrm{V}$ atoms which have lower atomic weight(50.94 amu) compared to that of Te (127.63 amu). 


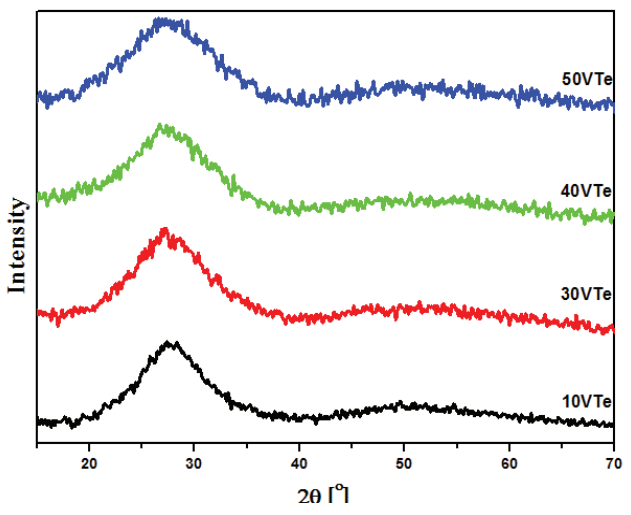

FIGURE 1. XRD patterns of $\mathrm{V}_{2} \mathrm{O}_{5}-\mathrm{TeO}_{2}$ glasses.

The thermodynamic fragility is calculated as:

$$
F=\frac{0.151+\chi}{0.151-\chi}
$$

where $\chi=\frac{\Delta T_{g}}{T_{g}} ; \Delta \mathrm{T}_{\mathrm{g}}$ is transition temperature width and it is defined as the difference between the onset point and end point. The fragility of the glasses decreases with increasing thevanadium oxide content.

TABLE 1.Density, molar volume, DSC data and fragility index of vanadium tellurite glasses.

\begin{tabular}{|c|c|c|c|c|c|c|c|c|c|c|}
\hline \multirow[t]{2}{*}{$\begin{array}{c}\text { Sample } \\
\text { Code }\end{array}$} & \multicolumn{2}{|c|}{$\begin{array}{c}\begin{array}{c}\text { Composition } \\
(\mathrm{mol} \%)\end{array} \\
\end{array}$} & \multirow[t]{2}{*}{$\begin{array}{l}\text { Density } \\
{\left[\mathrm{g} \mathrm{cm}^{-3}\right]}\end{array}$} & \multirow[t]{2}{*}{$\begin{array}{c}\mathrm{V}_{\mathrm{M}} \\
{\left[\mathrm{cm}^{3} \mathrm{~mol}^{-1}\right]}\end{array}$} & \multirow[t]{2}{*}{$\begin{array}{c}\mathbf{T}_{\mathbf{g}} \\
{\left[{ }^{\circ} \mathbf{C}\right]}\end{array}$} & \multicolumn{2}{|c|}{$\begin{array}{c}\mathbf{T}_{\mathbf{c}} \\
{\left[{ }^{0} \mathbf{C}\right]}\end{array}$} & \multirow[t]{2}{*}{$\begin{array}{c}\mathbf{T}_{\mathbf{m}} \\
{\left[{ }^{\circ} \mathbf{C}\right]}\end{array}$} & \multirow[t]{2}{*}{$\Delta \mathbf{T}_{\mathrm{g}}$} & \multirow[t]{2}{*}{$F=\frac{0.151+\chi}{0.151-\chi}$} \\
\hline & $\mathrm{V}_{2} \mathrm{O}_{5}$ & $\mathrm{TeO}_{2}$ & & & & $\mathbf{T}_{\mathrm{C} 1}$ & $T_{\mathrm{C} 2}$ & & & \\
\hline $10 \mathrm{VTe}$ & 10 & 90 & $5.22 \pm 0.04$ & 30.99 & 288 & 384 & - & 650 & 16 & 0.4624 \\
\hline $30 \mathrm{VTe}$ & 30 & 70 & $4.51 \pm 0.03$ & 36.80 & 255 & 309 & - & - & 23 & 0.2521 \\
\hline $40 \mathrm{VTe}$ & 40 & 60 & $4.22 \pm 0.01$ & 39.92 & 242 & 386 & 449 & 483 & 23 & 0.2259 \\
\hline $50 \mathrm{VTe}$ & 50 & 50 & $3.96 \pm 0.01$ & 43.07 & 232 & 317 & 452 & 480 & 24 & 0.1871 \\
\hline
\end{tabular}

The DSC patterns of all samples are shown in Figure 3. It is evident from DSC curves that there is one broad endothermic peak which corresponds to the transition temperature, $\mathrm{T}_{\mathrm{g}}$ followed by an exothermic peak representing crystallization temperature $T_{c}$ and as the vanadium oxide content increases,multiple crystallization peaks are observed due to the formation of differentcrystalline phases. From Table 1, it is clear that the value of transition temperature $\left(\mathrm{T}_{\mathrm{g}}\right)$ of $10 \mathrm{VTeO}$ is $288^{\circ} \mathrm{C}$ (midpoint) and $\mathrm{T}_{\mathrm{g}}$ decreases as the vanadium oxide content increases from 10 to $50 \mathrm{~mol} \%$ although V-O linkages have higher bond enthalpy $\left(644 \mathrm{~kJ} \mathrm{~mol}^{-1}\right)$ than Te-O $\left(376 \mathrm{~kJ} \mathrm{~mol}^{-1}\right)$. This can be explained by considering the fact that the glass transition temperature is a function of both $\mathrm{N}_{\mathrm{b}}$ and $\bar{F}$ i.e

$$
T_{g}=F\left(N_{b}, \overline{\mathcal{F}}\right)
$$

where $\bar{F}$ the average force constant of the glass network andN $\mathrm{N}_{\mathrm{b}}$ is the number of bonds per unit volume of the glass. Therefore, althoughthe average force constant $\bar{F}$ increases, the number of network bonds per unit volume $\left(\mathrm{N}_{\mathrm{b}}\right)$ gets decreased with increasing $\mathrm{V}_{2} \mathrm{O}_{5}$ content due to the formation of non-bridging oxygens [7]. Hence the glass transition temperature decreases from $288^{\circ} \mathrm{C}$ to $232^{\circ} \mathrm{C}$ with increasing $\mathrm{V}_{2} \mathrm{O}_{5}$ content.

Raman spectra of vanadium tellurite glasses are shown in Figure4. The band at $\sim 58 \mathrm{~cm}^{-1}$ is the boson peak, which is a universal feature of glassy phase[8]. The spectra show the four broad bands at $\sim 466,663,806$ and 908 $\mathrm{cm}^{-1}$. The band centered at $466 \mathrm{~cm}^{-1}$ is due to bending vibration modes of Te-O-Te linkages in $\mathrm{TeO}_{4}$ tbp units[2]. 


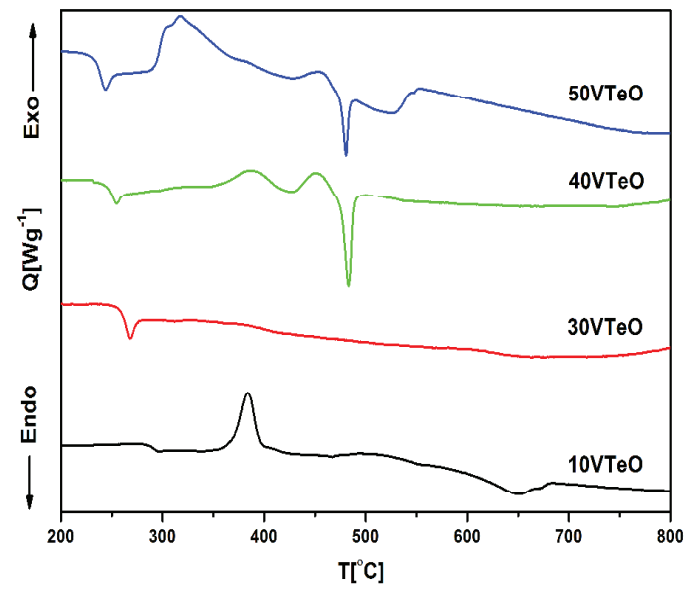

FIGURE 3. DSC patterns of $\mathrm{V}_{2} \mathrm{O}_{5}-\mathrm{TeO}_{2}$ glasses.

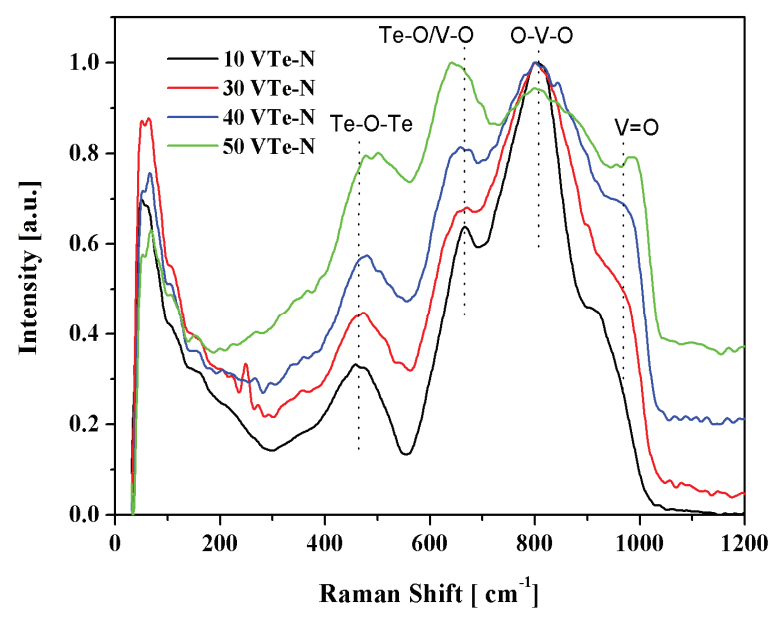

FIGURE 4.Raman spectra of $\mathrm{V}_{2} \mathrm{O}_{5}-\mathrm{TeO}_{2}$ glasses.

The peak at $663 \mathrm{~cm}^{-1}$ represents the Te-O/V-O vibrations, whereas the peaks at $806 \mathrm{~cm}^{-1}$ and $908 \mathrm{~cm}^{-1}$ are due to the $\mathrm{O}-\mathrm{V}-\mathrm{O}$ stretching vibrations and $\mathrm{V}=\mathrm{O}$ vibrations[9]. On increasing $\mathrm{V}_{2} \mathrm{O}_{5}$ concentration from 10 to $50 \mathrm{~mol} \%$, there is increase in the intensity of bands at $908 \mathrm{~cm}^{-1}$. The Te-O and V-O bands in Raman spectra are overlapping, hence it is not possible to determine Te-O co-ordination number from Raman studies.

\section{CONCLUSION}

$\mathrm{V}_{2} \mathrm{O}_{5}-\mathrm{TeO}_{2}$ glasses containing 10 to $50 \mathrm{~mol} \% \mathrm{~V}_{2} \mathrm{O}_{5}$ were prepared by melt quenching andcharacterized by X-ray diffraction, density measurements, DSC and Raman studies. Glass density, glass transition temperature and the fragility index decreases with increase in $\mathrm{V}_{2} \mathrm{O}_{5}$ concentration. Glass network becomes more open with increasing $\mathrm{V}_{2} \mathrm{O}_{5}$ concentration due to the formation of non-bridging oxygens.

\section{REFERENCES}

1. El-Mallawany, R.A., Tellurite glasses handbook: physical properties and data. 2011: CRC press.

2. Gupta, N., et al., Structure-property correlations in $\mathrm{TiO}_{2}-\mathrm{Bi}_{2} \mathrm{O}_{3}-\mathrm{B}_{2} \mathrm{O}_{3}-\mathrm{TeO}_{2}$ glasses. Journal of NonCrystalline Solids, 2017.

3. Tagiara, N., et al., Synthesis, thermal and structural properties of pure $\mathrm{TeO}_{2}$ glass and zinc-tellurite glasses. Journal of Non-Crystalline Solids, 2017. 457: p. 116-125.

4. Flynn, B.W., Electrical and optical properties of vanadium tellurite glasses. 1977.

5. Kaur, A., A. Khanna, and F. Gonzàlez. DSC and Raman studies of silver borotellurite glasses. in AIP Conference Proceedings. 2016: AIP Publishing.

6. Sidkey, M., et al., Ultrasonic studies of $\left(\mathrm{TeO}_{2}\right)(1-x)-\left(\mathrm{V}_{2} \mathrm{O}_{5}\right) x$ glasses. Journal of Non-Crystalline Solids, 1997. 215(1): p. 75-82.

7. El-Mallawany, R., et al., Volume and thermal studies for tellurite glasses. Journal of Materials Science, 2010. 45(4): p. 871-887.

8. Dutta, D. and A. Ghosh, Correlation of ion dynamics and structure of superionic tellurite glasses. The Journal of Chemical Physics, 2008. 128(4): p. 044511.

9. Baia, L., et al., Spectroscopic studies on the structure of vanadium tellurite glasses. Physics and Chemistry of Glasses, 2004. 45(3): p. 178-182. 